\title{
"Cuando a tu tierra le ponen precio y en otras tierras no te quieren" \\ Resistiendo la política del olvido y la resignación, de la política pública del desplazamiento forzado*
}

Jorge Arturo Salcedo Ramírez

\section{Introducción}

$\mathrm{H}^{\mathrm{l}}$ presente capítulo se propone demostrar que la política global Csobre las migraciones forzadas, para el caso colombiano, es una política del "olvido político y la resignación”. Para tal fin, se realiza un análisis gramsciano sobre las relaciones entre la agencia y estructura (Gramsci, 1971, p. 265), y entre la superestructura cultural y la infraestructura material (Gramsci, 1971, p. 367) que se constituyen en torno a las políticas sobre el desplazamiento forzado. Como elemento superestructural, la política sobre el desplazamiento crea las condiciones culturales, políticas y jurídicas necesarias para consolidar la

* Este capítulo es parte del trabajo de tesis doctoral de Jorge Arturo Salcedo R, del Doctorado en Derecho de la Universidad del Rosario, titulada "Las trayectorias del derecho al retorno: de la institucionalización internacional a la implementación local. El caso de la movilización política de la población desplazada de Turbo por el derecho al retorno". 
infraestructura material formada mediante el despojo territorial de las víctimas del desplazamiento como acumulación primitiva de capital (Harvey, 2004, p. 73). Para ello, el derecho contribuye a consolidar la superestructura cultural necesaria para reproducir la hegemonía de los sectores beneficiarios del despojo material y político producto del desplazamiento, mediante la consolidación de la resignación entre los desplazados frente a la pérdida de la autonomía y dignidad que tenían como campesinos, indígenas y afrodescendientes en sus territorios y tierras, ahora despojados. La política sobre el desplazamiento moviliza la aceptación entre estos últimos de un presente y futuro de precariedades y humillaciones en el nuevo lugar que les es asignado como desplazados y pobres urbanos, habitantes de barrios populares de las ciudades. En condiciones excepcionales, algunas comunidades de desplazados logran resistir el desplazamiento y el derecho sobre el desplazamiento mediante la disputa de los "lugares vitales", el derecho y la memoria.

La primera parte analiza la economía política del desplazamiento forzado en Colombia mostrando los intereses explícitos e implícitos que se movilizan con este último, en el contexto de las políticas de defensa y seguridad nacional heredadas de la Guerra Fría, de carácter contrainsurgente, y los modelos económicos que se promueven mediante las mismas. Identifica las políticas superestructurales y sus resultados infraestructurales en la economía, así como el papel de los agentes o actores en dicha interacción en torno a los bloques hegemónico y contrahegemónicos. La segunda sección caracteriza la política global de migraciones forzadas en el marco del derecho internacional de refugiados y del derecho de los desplazados internos, como factores migratorios push que constriñen a los desplazados a ocupar el lugar de pobres urbanos. En especial, explica la funcionalidad del derecho sobre los desplazamientos forzados para consolidar los efectos políticos y económicos de la violencia como factor push en su origen. La tercera parte muestra el derecho del desplazamiento interno como una máquina despolitizadora que procura la reconfiguración de la identidad sociocultural de quienes sufren este delito desde sus identidades tradicionales hacia las transicionales, consolidando el olvido buscado intencionalmente por las políticas del horror que forzaron el 
desplazamiento. La cuarta sección presenta algunas experiencias de resistencia al desplazamiento y a los efectos simbólicos del derecho sobre el desplazamiento, emprendidas mediante acciones colectivas que usan el derecho al retorno como bandera política para disputarse su garantía efectiva y en las que el horror no logra borrar sus recuerdos y deseos de volver a la vida anterior. La quinta y última parte presenta las concluciones.

\section{La economía política del desplazamiento forzado en el contexto de las políticas de defensa y seguridad nacional: entre el poder sin ley y el derecho sin poder}

No deja de resultar paradójico que el conflicto armado colombiano, originado en el contexto de la Guerra Fría entre los bloques globales capitalista y comunista, resultó mucho más virulento y destructivo para la sociedad colombiana justo en el momento en que esta confrontación global terminaba a finales de los años ochenta. El fin de la Guerra Fría lejos de acabar, o siquiera reducir la intensidad de la violencia que acompañaba el conflicto interno armado en Colombia, significó una degradación humanitaria sin precedentes en su historia. Los indicadores de violencia política, particularmente de violaciones a los derechos humanos e infracciones al derecho internacional humanitario, incluyendo el desplazamiento forzado y el despojo, estallan y se degradan a finales de los años ochenta, elevándose exponencialmente durante la segunda mitad de la década de los años noventa, hasta alcanzar su clímax en la década del 2000, y acumulando hasta inicios del 2017 alrededor de ocho millones de víctimas, en su mayoría población desplazada proveniente del campo (Uaeriv, 2017).

Después del fin de la Guerra Fría, el conflicto armado colombiano se hizo mas complejo. Si bien mantuvo las motivaciones políticas que fueron preponderantes durante esta última, esas motivaciones se amalgamaron con las motivaciones económicas derivadas del interés de los actores en conflicto de capturar rentas económicas legales e ilegales (González, 2014). En efecto, el conflicto armado heredó las líneas 
de división geopolítica e ideológica distintivas de la disputa global entre comunismo y capitalismo. Adaptada al contexto colombiano, esta disputa se expresó en la confrontación de larga duración entre modelos de sociedad liberales y neoliberales, y modelos que, sin pretender la colectivización soviética o cubana de la sociedad (Tobón, 2001), sí afirmaban desde una oposición contrahegemónica de izquierda, la defensa de las intereses de sectores subalternos desde perspectivas socialdemócratas. En especial, la defensa de las economías rurales campesinas, afrodescendientes e indígenas, y de los intereses de sectores subalternos urbanos como los pobladores, estudiantes y trabajadores. De otro lado, el conflicto armado estuvo motivado por los intereses de los actores en disputa de capturar rentas de la economía legal entre otras, mediante la corrupción, la extorsión, el despojo y el secuestro, y de la economía ilegal derivadas de las extraordinarias rentas del narcotráfico mediante el control de la producción o el cobro de impuestos al mismo. Lo mismo sucedió con los factores del reclutamiento de combatientes por parte de los diferentes actores, quienes vincularon a sus filas población motivada por una combinación de razones políticas como de supervivencia y acumulación económica.

La terminación de la confrontación global entre comunismo y capitalismo tampoco significó en Colombia la desaparición del componente clasista de la violencia sociopolítica. A pesar de la complejidad de la nueva dinámica de todos contra todos donde el conjunto de los sectores sociales y políticos resultaron victimarios y victimizados, el conflicto armado mantuvo como contradicción mayor la disputa entre los bloques hegemónicos y contrahegemónicos; y como contradicciones menores, disputas al interior de cada bloque clasista. La contradicción mayor se desarrolló entre alianzas inestables y cambiantes no exentas de conflictos entre sí, integradas por las fuerzas armadas, agentes civiles del Estado, élites políticas y económicas tradicionales, y las élites emergentes integradas por los narcotraficantes con sus ejércitos paramilitares y con el apoyo del gobierno de los Estados Unidos, que se enfrentaron mediante estrategias contrainsurgentes, a convergencias igualmente inestables y cambiantes entre guerrillas, partidos políticos de izquierda, movimientos sociales urbanos y rurales, quienes también presentaron contradicciones internas que alcanzaron incluso 
la violencia abierta entre sus integrantes. Las contradicciones menores se dieron al interior del bloque hegemónico entre sectores de las élites legales e ilegales emergentes, como los partidos tradicionales, empresarios legales, el Cartel de Cali y posteriormente las AUC, contra élites legales e ilegales en cabeza de sectores de los partidos tradicionales y el Cartel de Medellín. Al interior del bloque contrahegemónico se destacan las disputas entre las guerrillas de las Farc, del ELN y en su momento del EPL que se extendieron al conjunto de sus aliados en la sociedad civil. Las alianzas entre guerrillas y narcoparamilitares en torno a los eslabones iniciales de la producción de cocaína y cultivo de la hoja de coca en las zonas de dominio guerrillero, no fueron óbice para que estos se enfrentaran por el control territorial de las zonas más integradas y estratégicas del país.

Las alianzas contrainsurgentes entre élites legales e ilegales se articularon en torno a la Política de Defensa y Seguridad Nacional bajo la doctrina del "enemigo interno" heredada de la influencia militar norteamericana para combatir el comunismo internacional implementada en Latinoamérica. En Colombia, la recepción de dicha doctrina no significó la imposición de una dictadura militar como sucedió en el resto del continente, sino el estrechamiento del régimen político con exclusión de los partidos izquierdistas, elevadas prerrogativas militares frente a un débil control civil, el abuso de la figura del Estado de Sitio y la promoción del paramilitarismo después del fin de la Guerra Fría (Leal, 2003). Esta estrategia contrainsurgente concentró sus ataques contra la población civil, la cual era visualizada como real o potencial aliada de la insurgencia armada, convirtiéndose en blanco de ataques bajo el lema de "quitarle el agua al pez". El argumento contrainsurgente también fue utilizado como excusa y discurso legitimador del exterminio del conjunto del movimiento social y político de oposición con independencia de su cercanía o no a las insurgencias armadas (Gutierrez y Barón, 2004). Para ello se implementaron de forma sistemática tecnologías del horror con el fin de generar un impacto simbólico, económico y político desestructurador, orientado a desmovilizar políticamente los sectores sociales de oposición más empoderados. El horror produce un olvido político de las banderas que enarbolaban y de las conquistas económicas y sociales logradas mediante dichas luchas, 
producto del dolor sufrido que termina por impregnar los recuerdos de las luchas y conquistas hasta hacerlos insoportables para muchos.

La estrategia contrainsurgente de la Posguerra Fría colombiana se caracterizó por combinar todas las formas de lucha desde una política de outsourcing del horror. En efecto, durante la Guerra Fría, el régimen político colombiano emprendió políticas de tierra arrasada de las insurgencias y de criminalización de los movimientos sociales y políticos de oposición; mediante detenciones arbitrarias y desapariciones forzadas en cabeza de los organismos de seguridad del Estado. Esto tuvo como consecuencia altos costos políticos internos e internacionales por la responsabilidad, por acción en la violación de los derechos humanos, destacándose el Estatuto de Seguridad de Turbay Ayala (1978-1982). En la Posguerra Fría, se registra una división social del trabajo contrainsurgente en la que se delega en grupos narcoparamilitares la eliminación sistemática de cualquier forma organizativa social y política de oposición, intentando con ello proyectar una imagen de independencia frente al establishment y reducir el costo político interno e internacional al Estado. El paramilitarismo ejecuta operaciones psicológicas contra los sectores sociales políticamente movilizados mediante las tácticas del horror y una guerra económica consistente en la captura de tierras, territorios y rentas. El componente de combate militar a las guerrillas es encabezado por una fuerza pública cada vez más fortalecida, con apoyo directo del gobierno estadounidense y una participación cada vez mayor del Рів. El trabajo conjunto entre fuerzas armadas y narcoparamilitares, y sus aliados en la política y en la economía, produce el desplazamiento masivo de las bases sociales de los sectores sociales y políticos más vulnerables; principalmente de los campesinos, indígenas y afrodescendientes que habían conquistado el acceso a la tierra y al territorio mediante luchas históricas y grandes sacrificios. El desplazamiento se traduce en el despojo de entre dos y diez millones de hectáreas dependiendo de las fuente, principalmente acaparadas por paramilitares, testaferros y herederos (CNMH, 2016).

Mediante las políticas contrainsurgentes se crean las condiciones políticas necesarias para facilitar la consolidación del neoliberalismo en Colombia, cuya aproximación doméstica se tradujo en una especie de capitalismo armado con rasgos neofeudales. Caracterizados por la 
concentración extrema de la tierra y de la riqueza, y la total impunidad de los responsables no solo para mantener el despojo sino para consolidar dominios territoriales e institucionales mafiosos. Todo lo anterior ha sido legitimado como una lucha en defensa de la libertad, la propiedad y la democracia, contra el comunismo internacional, el terrorismo y el narcotráfico (Cruz, 2009). El despojo vehiculado con el desplazamiento no se limitó solo a la enajenación forzosa de los predios, sino que implicó la reconfiguración forzada de los ordenamientos políticos, económicos y socioculturales preexistentes hacia unos nuevos intereses rentísticos de quienes logran capturarlos mediante el uso de la violencia extrema. Mientras en el contexto del cono sur, el neoliberalismo tuvo un proceso de avanzada con las dictaduras militares de la Guerra Fría, en Colombia este modelo político-económico irrumpirá con mayor fuerza a partir de los años noventa en el contexto del auge del desplazamiento y el despojo, y de la implementación de políticas neoliberales como la liberación de importaciones, las privatizaciones y el desmonte de las reformas progresistas en materia laboral, de educación y salud. No dejan de ser paradójicos los avances en materia constitucional y legal que se acompañan de retrocesos en materia política y de realización material de los derechos, que se registran en el tránsito entre las Constituciones de 1886 y de 1991. Durante las últimas tres décadas de vigencia de la Constitución de 1886, una carta limitada en materia de derechos, participación política y mecanismos de defensa de los mismos, los movimientos campesino, indígena, obrero, estudiantil y de izquierda partidista lograron los mayores niveles de acción colectiva y empoderamiento, y de conquistas sociales y materiales de la historia reciente del país. Por el contrario, durante el mandato de la Constitución de 1991 en lo formal una constitución para ángeles por la extensa carta de derechos y mecanismos para garantizarlos, dichos movimientos son desarticulados o debilitados, y sus principales conquistas territoriales y materiales despojadas. Con notables excepciones como la del movimiento indígena del Norte del Cauca que, además de mantener sus niveles de organización, han logrado conservar sus conquistas territoriales y políticas como se ve más adelante.

Como resultado de este proceso, sectores de las élites dominantes capturan secciones del Estado para ejercer un poder sin límites contra la población civil real o supuestamente base de apoyo de las insurgencias, 
mediante el paramilitarismo y violaciones masivas a los derechos humanos, en medio de la mayor impunidad. Una vez desestructuradas las comunidades políticas campesinas mediante las tácticas del horror, a cambio les otorgan el marco legal sobre el desplazamiento a personas sin capacidad política real de incidir en su implementación. En pocas palabras, mediante un poder sin ley, las élites arrasan a las comunidades campesinas, a las que, una vez desplazadas, otorgan una ley sin poder real para devolverlas a la situación anterior, al desplazamiento.

\section{La política global de migraciones forzadas: ni refugio internacional ni retorno interno}

Con la caída del muro de Berlín y la disolución de la uRss, la política global de migraciones forzadas se transforma. Las potencias capitalistas pasaron de privilegiar el refugio y el derecho a no ser sujeto de devolución durante la Guerra Fría, como una forma de deslegitimar los regímenes comunistas como violadores de los derechos humanos (Bradley, 2013, p. 3), a intentar reducir la internacionalización de la migración forzada mediante la priorización de la repatriación y el confinamiento del desplazamiento al interior de las fronteras de los países de origen sin importar las calidades democráticas de los Estados expulsores (Cohen, 2007, p. 372). A partir de los años noventa, se enfatiza el componente de repatriación del DIR buscando devolver a los refugiados, mientras se inicia un proceso de debilitamiento del régimen del refugio mediante interpretaciones restrictivas de la calidad de refugiado, la reducción de las cuotas de recepción, entre otras medidas (Bradley, 2013). La reducción del refugio se complementa con medidas extraterritoriales y securitizadas de control de los flujos migratorios, como el caso actual de la Unión Europea frente a los flujos africanos y del Medio Oriente usando a Libia y Turquía respectivamente como barreras de contención, y los vetos migratorios de la administración estadounidense de Trump. Al mismo tiempo, se instituye el régimen internacional sobre los desplazamientos con la expedición de los "Principios Rectores sobre los desplazamientos internos" (ONU,1998), que busca confinar al interior de las fronteras nacionales de los Estados expulsores a los desplazados internos, descargando la responsabilidad de su atención 
y manejo en los mismos, con cierto apoyo residual de los países desarrollados y las agencias internacionales (Vidal, 2005).

Ambas estrategias, la del uso político del Dir enfatizando la repatriación y la institucionalización del derecho sobre los desplazados internos, buscan prevenir la internacionalización de los desplazamientos como refugiados, mediante su contención al interior de sus países de origen como desplazados internos. Sin embargo, la política global de migraciones forzadas tiene otro vector en dirección opuesta a la anterior; y es la de evitar el retorno a las tierras de origen de los desplazados cuando las mismas tienen un interés estratégico económico o político para las élites nacionales e internacionales, los Estados y los órganos internacionales. Es decir, los desplazados se enfrentan a dos fuerzas migratorias: una que los rechaza cuando intentan encontrar protección en otros países y otra que los amenaza para no volver a sus tierras de origen, cuando estas tienen un valor estratégico para intereses político y económicos capitalistas nacionales y transnacionales.

A pesar de los cientos de miles de colombianos desplazados que han obtenido el estatus de refugiado o que han logrado retornar a sus tierras de origen, estos representan la excepción en comparación con los que quedan atrapados en el limbo migratorio sin poder partir a otras tierras a buscar mejores oportunidades ni regresar a sus tierras, viéndose confinados en los barrios populares de las grandes ciudades colombianas. De los más de siete millones de desplazados, alrededor de 360000 han logrado acceder a la condición de refugiado (Acnur, 2017) y menos de 500000 han retornado (El Tiempo, 2015). Los demás se encuentran confinados en las barriadas populares de las grandes ciudades sufriendo toda clase de precariedades.

\section{El derecho sobre el desplazamiento interno como máquina despolitizadora: entre el olvido de las luchas agrarias y políticas, y la resignación en el presente como desplazados urbanizados}

La implementación nacional de la nueva política global sobre migraciones forzadas, se lleva a cabo mediante el marco jurídico del desplazamiento forzado contenido en las leyes: Ley 387 de 1997 de Atención 
Integral a la Población Desplazada, Ley 975 de 2005 de Justicia y Paz, y Ley 1448 de 2011 de Víctimas y Restitución de Tierras. Este marco jurídico se caracteriza por desconocer las causas políticas y económicas del desplazamiento y del conflicto armado, con excepción del despojo y abandono de tierras que se aborda en las dos últimas normas y que es uno de los trasfondos del mismo. El desplazamiento es codificado en un lenguaje despolitizado que lo nombra como un hecho victimizante y que explica su origen como resultado de situaciones de violencia particulares, incluido el conflicto interno armado, pero no como un proceso político de construcción violenta del Estado-nación colombiano desde un modelo neoliberal (Fadnes y Horst, 2009). Este marco normativo es utilizado como discurso político por parte de la institucionalidad y la burocracia, el cual tiene una elevada eficacia simbólica para reconfigurar las identidades de quienes sufren dichos delitos que transitan de identificarse como indígenas, afros o campesinos, a ser desplazados o víctimas del desplazamiento.

Aunque el marco legal sobre el desplazamiento reconoce la existencia de otras identidades de los desplazados, todavía a nivel étnico y de género, entre otros, la fuerza de la carga simbólica de las categorías de víctimas y desplazados termina por subsumir dicho reconocimiento. Así mismo, el campesinado no ha sido un sujeto político reconocido por este marco al mismo nivel que lo hace con los indígenas y los afrodescendientes. La débil enunciación de las identidades de los desplazados en el marco legal y la ausencia de un enfoque de reparación estructural en la política sobre el desplazamiento, son reforzadas por los impactos socioculturales del prolongado desarraigo y falta de conexión con la tierra y el territorio, y la consecuente reconfiguración de sus identidades originarias como campesinos, indígenas y afros. El recuerdo de los espacios políticos y territoriales que alguna vez se conquistaron y ganaron, como las intensas luchas individuales y colectivas, ahora son impregnadas por el recuerdo del dolor y el horror del cual es difícil separarse, dando paso a un proceso de olvido en el sentido político y colectivo. Olvido apuntalado por un modelo de desarrollo que, a pesar de sus enunciados progresistas, desconoce los pobladores rurales populares y sus intereses para privilegiar el ordenamiento neoliberal del agro. 
El marco jurídico transicional prevé acciones de memoria y verdad a partir de las cual se producen informes de memoria por parte de entidades estatales sobre casos y procesos emblemáticos, en la mayoría de los casos muy completos y bien elaborados. Sin embargo, en el caso de la población desplazada y a pesar de las acciones pedagógicas de divulgación de dichos informes, estos no logran convertirse en marcos culturales para la acción política colectiva de reivindicación de los reclamos de justicia social. Los cuales enarbolaron antes del desplazamiento en los nuevos contextos, y fue una de las razones por las que los victimizaron buscando su desarticulación organizativa. Los informes y acciones de memoria gestionados por entidades estatales nacionales a pesar de la alta calidad académica de muchos de ellos, tiene dificultades para instaurarse en el tejido social, y en los espacios cotidianos y locales de acción política de las víctimas del desplazamiento, y para movilizar agendas políticas estructurales alrededor del modelo de mercado y Estado más allá de las reivindicaciones de sus derechos transicionales como víctimas.

Ante la ausencia de alternativas emancipadoras como el retorno a sus tierras o el refugio en tierras prometidas en países desarrollados, los desplazados han quedado sometidos al único espacio institucional que se les ha ofrecido como víctimas del desplazamiento interno para exigir del Estado el cumplimiento de lo escrito en las normas jurídicas. Han sido relegados al único espacio físico-espacial posible para ellos: "pobres urbanos" residentes en los barrios marginales. Menos del $7 \%$ de los desplazados logran retornar a sus tierras (El Tiempo, 2015), y dicho retorno cuando se logra no siempre es sostenible ni implica que se revierta la reconfiguración de sus territorios. La política de restitución no ha desencadenado en escalas mínimamente significativas el retorno ni la restitución de las tierras despojadas. La pérdida de las tierras, del territorio y del poder social y político construido antes del desplazamiento, es reparada por el Estado mediante una serie de medidas que, en últimas, afianzan la aceptación de los desplazados de sus nuevos destinos como "pobres urbanos". Entre otros, les otorga una indemnización en dinero que tarda en llegar y que no posibilita una solución duradera por el monto y la imposibilidad de volverla productiva en mercados urbanos altamente competitivos. Les 
concede ayudas humanitarias temporales, brinda acceso a servicios de salud y educación relativamente aceptables en las ciudades, ofrece acciones simbólicas puntuales, adelanta —en algunos casos- procesos de reparación colectiva que no logran restaurar las conquistas estructurales obtenidas por los desplazados antes de su desarraigo, a veces les otorga una vivienda gratis solo si se ganan la lotería de ser seleccionados, se publican informes de memoria histórica sin que los mismos se traduzcan necesariamente en el castigo o sanción judicial o política de los responsables de sus tragedias, se les dan capacitaciones - muchas de las cuales no les sirve para nada- y se ofrecen espacios formales de participación que no inciden en el diseño estructural de una política.

Las personas desplazadas del campo dejan de ser campesinas, indígenas y afros en control de territorios productivos con fuentes agua, alimento y paisaje, y pierden la autonomía colectiva que habían ganado con muertos y luchas de larga duración. En el nuevo escenario, como desplazados urbanizados, se vuelven esclavos sin tierra, sin comunidad ni redes de apoyo, deben vender su fuerza de trabajo por cualquier jornal o servicio prestado, las mujeres se exponen al acoso laboral y sexual como empleadas domésticas, otras no tienen más opciones que el trabajo sexual, los jóvenes son presa fácil del reclutamiento de las bandas criminales urbanas y el consumo de estupefacientes. Ahora les toca pagar por la comida, el arriendo, los servicios e incluso por la vida cuando son extorsionados por los grupos criminales, en barrios de pésima calidad de vivienda y urbanismo, en medio del hacinamiento, sin paisajes y sin seguridad. En el nuevo lugar como "pobres urbanos", la desconfianza se vuelve la norma, la disolución del tejido social y la anomia. Se facilita su control social por medio de las redes de criminalidad que gobiernan los barrios en el marco de cadenas de mando cuyos centros de poder se ubican en barrios ricos de la ciudad, y que frecuentemente llegan hasta los niveles de control político superiores. En Colombia, a diferencia de países africanos y asiáticos, no existen campos para los desplazados internos. Pero los barrios a donde llegan integrados por diferentes generaciones de desplazados forzados, contienen lógicas de control biopolítico semejantes a esos campos: control poblacional, control del movimiento y el hábitat, y desarticulación de 
la acción colectiva. Las políticas de control del espacio urbano por las autoridades locales complementan su confinamiento en dichos barrios, mediante la persecución y desalojo contra los vendedores ambulantes por medio del derecho policivo.

En el nuevo contexto, la movilización política de los desplazados, cuando se logra, se articula alrededor de las identidades legales como víctima del desplazamiento, ya no para reclamar el derecho a retornar a la tierra y al territorio — que se vuelve más una exigencia retórica, con contadas excepciones que se verán más adelante- sino para reclamar ayudas humanitarias, el pago de las indemnizaciones, el proyecto producto y tener una vivienda urbana. Mediante tomas de espacios públicos y sedes de edificios gubernamentales consiguen algunas concesiones. Se conforman miles de organizaciones de desplazados atomizadas sin capacidad de articular acciones colectivas de envergadura para exigir cambios estructurales a su situación. La división y la disputa por los cargos de representación y escasos recursos de reparación colectiva termina dividiéndolos aún mas, haciéndolos presa fácil del clientelismo tradicional de los partidos hegemónicos. La participación se institucionaliza en las mesas de víctimas donde no tienen mayor capacidad de incidencia real. Se produce una politización de la vida pero alrededor de la defensa de la condición legal de víctima del desplazamiento, que tiene una dimensión principalmente de reclamo individual de derechos y una condición despolitizadora.

La política de la resignación cumple su cometido. Las luchas históricas como banderas y discursos políticos para enmarcar la movilización social por los derechos al territorio y a la vida digna son reemplazadas —en el mejor de los casos- por acciones colectivas para reclamar los subsidios no sostenibles que les ofrece el marco jurídico. Si bien el retorno y el refugio le son negados a la inmensa mayoría de los desplazados, el hecho que aparezcan enunciadas en la normatividad, comunicadas por la institucionalidad y acompañadas de algunos casos reales, genera la sensación de la posibilidad de elegir, por lejana o inviable que sean dichas opciones. La restitución de tierras autogestionadas por parte de los desplazados, no logra articular acciones colectivas a nivel nacional que posibiliten avanzar en la guerra de posiciones de las luchas contrahegemónicas más allá de los territorios 
locales. Muchas veces la restitución llega cuando los titulares están muertos o demasiado viejos para regresar, y sus herederos se han urbanizado. Las pérdidas de unos son las ganancias de otros. Mientras los desplazados padecen toda clase de penurias en las ciudades, sus territorios despojados son usufructuados por las élites políticas y económicas, tradicionales y emergentes, que han controlado las fuentes de riqueza y el aparato del Estado. Élites que se disputan entre sí el territorio desalojado y despojado como botín de guerra, con diferencias de matices pero estructuralmente identificados en el modelo neoliberal. Haciendo del país uno de los más desiguales del mundo, principalmente en materia agraria (Igac, 2016). Los fenómenos de la parapolítica y de la paraeconomía — aún no esclarecidos totalmente- evidencian la complicidad de las élites con el despojo y el desplazamiento.

En la coyuntura del presente, el discurso oficial frente al retorno se articula alrededor del Acuerdo de Paz con las Farc mediante el cual se promete una doble transición en el país: del conflicto armado con esa guerrilla a la paz negativa, y de una democracia imperfecta a una democracia más justa e incluyente como paz positiva. Lo primero se ha empezado a evidenciar con la caída de los indicadores de la confrontación armada, aunque persisten infracciones al DIH y violaciones a los DDHH con el asesinato de centenares de líderes sociales. Lo segundo augura contradicciones desde el inicio, porque mientras el gobierno se comprometía con medidas progresistas en materia rural en el Acuerdo, en la práctica viene implementando medidas contrarias como la ley de las Zidres, y la multiplicación de las licencias mineras en todo el territorio que privilegian la minería empresarial por encima de la artesanal, y de los derechos colectivos de las comunidades afectadas por la explotación a gran escala de los recursos naturales. Una ganancia inequívoca del Acuerdo de Paz, es la posibilidad de una primavera colombiana. Es decir, de un renacer de los movimientos sociales que ahora, sin el estigma de ser terroristas o subversivos, pueden mejorar la articulación de sus luchas, incluyendo las luchas por el retorno de sectores agrarios desplazados y despojados. No obstante, la persistencia del ELN en la lucha armada puede servir de excusa final para mantener dicha estigmatización. Además, no están claras las garantías para la movilización política de oposición en el posacuerdo con 
las Farc. El nuevo paramilitarismo y las políticas oficiales contrainsurgentes se encuentran, probablemente, detrás de los nuevos asesinatos de centenares de líderes sociales y políticos de oposición, que se realizan bajo la mayor impunidad y en el marco de renovados procesos de criminalización de la protesta social. Más allá de acciones puntuales de restitución que resultan marginales frente al tamaño del despojo y del desplazamiento, el despojo territorial y político de los sectores subalternos amenaza con consolidarse por la vía del proceso de paz, gracias al cual el Estado puede mejorar las opciones para integrar los territorios que se encontraban bajo control de las Farc a los mercados internacionales de materias primas. Aunque los ex guerrilleros de las Farc prometen mantener sus luchas por un país más justo, y por una dignificación de los campesinos, indígenas, afros y sectores urbanos, las locomotoras del desarrollo defendidas con políticas contrainsurgentes y paraestatales parecen aplanadoras ante las cuales parecer difícil, o imposible, ejercer una resistencia efectiva.

\section{Algunas experiencias de resistencia al desplazamiento y a los efectos simbólicos del derecho: retornos auto gestionados, memorias hibridas y control territorial}

En medio del desolador panorama, emergen contadas pero significativas experiencias de resistencia tanto al desplazamiento como a los efectos despolitizadores del marco jurídico. Son experiencias que se caracterizan por un control relativo de los territorios que habían abandonado o les fueron despojados, por el uso estratégico del derecho oficial, tanto el ordinario como el transicional, y por las nuevas luchas colectivas por el retorno enmarcadas en una memoria híbrida que recoge lo mejor de sus luchas agrarias anteriores y las recontextualizan de forma estratégica con las nuevas identidades legales como víctimas y desplazados. Estas experiencias representan un porcentaje ínfimo de los desplazados en el país, pero son enormemente significativas para los factores explicativos de estos procesos de resistencia.

Entre los retornos como formas de resistencia al desplazamiento forzado y al despojo, pero también como formas de resistencia a 
la política pública del desplazamiento como política del olvido y la resignación, emergen experiencias entre indígenas, campesinos y comunidades negras. Entre muchos otros, se destacan las comunidades indígenas del norte del Cauca del municipio de Toribio que fueron desplazados en el 2005 por combates entre la fuerza pública y las Farc, las cuales retornaron en el mismo año gracias a la estrategia de minga por la vida y guardia indígena; las comunidades negras del bajo Atrato desplazadas a mediados de los años noventa organizadas como comunidades de biodiversidad y de resistencia; los campesinos organizados como la Comunidad de Paz de San José de Apartadó, desplazados igualmente a mediados de los años noventa y quienes retornan colectivamente pocos años después (Vidal y otros 2011); los campesinos de Turbo articulados en torno a Tierra y Vida, ahora llamados Tierra y Paz, que son también desplazados a mediados de los años noventa y lograron retornar en la segunda mitad de la década del 2000 en medio del asesinato de más de diez de sus líderes (IPC, 2012)

Estas experiencias tienen como común denominador haber conquistado el acceso a sus tierras con títulos de propiedad formales, haber logrado dicho acceso gracias a movilizaciones políticas amplias y de mediana duración, y contar con recursos simbólicos identitarios para movilizar la acción colectiva basados en referentes socioculturales de la vida en el campo como campesinos, indígenas y afros. Se trata de comunidades rurales que antes de ser desplazadas y despojadas fueron ganadoras tanto de espacios políticos reflejados en la amplitud y fuerza de sus organizaciones, como de espacios físicos representados en sus tierras y territorios rurales. Gracias a estas conquistas construyeron unas narrativas y unas cosmovisiones frente al habitar de esos espacios. A pesar del terror que les fue impregnado por la violencia sistemática ejercida principalmente por grupos paramilitares con apoyo de sectores oficiales, las memorias de la vida en el campo fueron más fuertes que las memorias del horror que los vio salir, esto facilitó su encuadre como discurso político para la nueva movilización dirigida al retorno y a la recuperación de sus tierras y modos de vida. Las trayectorias del desplazamiento que recorrieron fueron menores, siempre estuvieron relativamente cerca de sus tierras y mantuvieron un contacto entre ellos. Contaron con el apoyo de organizaciones nacionales e 
internacionales, acompañantes que les ayudaron a estructurar el marco jurídico y a realizar acciones de incidencia ante autoridades y órganos internacionales. Interpelaron los mecanismos jurídicos de la justicia transicional, y también activaron mecanismos del derecho ordinario, pero siempre bajo la consciencia que, antes que ser desplazados o víctimas del desplazamiento, eran comunidades políticas de campesinos, indígenas y afros llenos de dignidad dispuestos a sacrificar sus vidas por reclamar su derecho a retornar a sus tierras. Se trató en todos los casos de retornos no acompañados por la institucionalidad e incluso dificultados por la misma en ciertos casos, como el de Turbo, donde la fuerza pública intentó impedir la recuperación de predios despojados por parte de los campesinos organizados, o el de San José de Apartadó, donde miembros del Ejército participaron de una masacre de personas retornantes de esa comunidad.

Las memorias fueron un factor para la resistencia al desplazamiento y al derecho sobre el desplazamiento, y un motor para movilizarse políticamente a favor de su retorno. Estas comunidades lograron sobreponer los recuerdos de la vida buena antes del desplazamiento y de las luchas por conquistarla, a las memorias del horror al momento de la huida. La memoria del desplazamiento incrementó el deseo de retorno entre estas comunidades, el cual se motivó por los recuerdos de ese periodo en que permanecen por fuera de sus tierras, en un limbo en el que pierden la autonomía existencial para volverse empleados o esclavos en un contexto de destierro, sin autonomía alimentaria, habitacional, comunitaria y política. Las memorias de la bumillación han sido un factor que los aleja de los lugares de integración temporal y propicia el retorno.

En el caso de los campesinos y de los afros, la resistencia ante la intensidad y prolongación del despojo y del desplazamiento en el marco del retorno a la tierra, excluye de los repertorios de acción colectiva la reivindicación de reclamos de justicia distributiva estructural en materia de reforma agraria de campesinos sin tierras, y se limita a las reivindicaciones de justicia transicional coyuntural delimitada a la restitución de tierras despojadas. Se presenta así un segundo efecto despolitizador en quienes logran articular algún nivel de resistencia, pues deben tomar distancia de los campesinos sin tierra para evitar 
ser tachados de invasores de tierras. Adicionalmente, se registran dificultades para que las acciones colectivas orientadas a la restitución de las tierras despojadas transciendan los espacios locales y logren articular procesos de movilización a escalas interregionales y nacional.

\section{Conclusiones}

La política global sobre migración forzada y su expresión nacional en Colombia opera en diferentes niveles: en la agencia, la estructura, la superestructura y la infraestructura. La violencia extrema y el derecho del desplazamiento juntos son superestructuras que facilitan la reconfiguración de los sujetos políticos populares que controlan los territorios requeridos para los imperativos de la globalización neoliberal. Una vez habitan los barrios pobres, los desplazados son sometidos a control social gracias a las redes de criminalidad que operan en los mismos. A nivel de la agencia, mediante sofisticadas operaciones simbólicas, el derecho sobre las víctimas del desplazamiento ofrece una nueva identidad basada en las categorías legales, que ofrece una supuesta solución al callejón cerrado que significa la imposibilidad de volver a la tierra de origen o de refugiarse en países desarrollados. Este tránsito identitario se facilita gracias a las memorias del horror que logran contaminar emocionalmente los espacios sociales, físicos y políticos conquistados antes del desplazamiento, que tienden a ser olvidados como banderas políticas por el dolor que produce su recuerdo y el temor a la repetición. Las experiencias de politización previas para defender los territorios rurales se transforman en movilizaciones atomizadas de desplazados urbanizados por la subsistencia alrededor de los subsidios estatales temporales en un contexto territorial de desarraigo, segregación urbana y atomización social. A nivel de la infraestructura, las políticas globales logran reconfigurar territorios en escalas masivas, y moldearlos a conveniencia de los poderes trasnacionales y sus aliados nacionales en torno a paradigmas neoliberales de organización de la vida. Las posibilidades emancipatorias y contrahegemónicas de los desplazados frente al desplazamiento y al marco jurídico que lo regula, son mínimas pero existentes. Los casos en los que han podido articular alguna forma de resistencia colectiva, 
muestra relaciones entre agencia y estructura, caracterizadas por la conjunción de historias de movilización social y política de sujetos sociales subalternos rurales que logran —mediante las mismas- acceder a la tierra y construir territorialidades propias con elevados niveles de autonomía. Las memorias de procesos exitosos de acción colectiva para conseguir transformaciones estructurales, así sea a escala local, parecen ser uno de los factores explicativos cruciales de los procesos relativamente exitosos en que los desplazados logran oponerse al desplazamiento y al despojo mediante la movilización política y el uso estratégico del derecho.

\section{Referencias bibliográficas}

Bradley, M. (2013). Refugee Repatriation: Justice, Reponsability and Redress. Cambridge: Cambridge Univesity Press.

CNMH. (2013). ¡Basta ya! Colombia: Memorias de guerra y dignidad. Bogotá: CNMH.

CNMH. (2016). Tierras y conflictos rurales Historia, politicas agrarias y protagonistas. Bogotá: CNMH.

Cohen, R. (2007). Response to Hathaway. Journal of Refugee Studies, 20(3), 370.

Cruz, E. (2009). Discurso y legitimación del paramilitarismo en Colombia: Tras las huellas del proyecto hegemónico. Ciencia Política, 8 , julio-diciembre.

El Tiempo. (16 febrero de 2015). Desplazamiento en Colombia. Encuesta de Víctimas. En línea. Recuperado de: http://www.eltiempo.com/politica/justicia/ desplazamiento-en-colombia-encuesta-de-unidad-de-victimas/15104675

Fadnes, E. y Horst, C. (2009). Responses to Internal Displacement in Colombia Guided by What Principles? Refuge, 26 (1), 111.

Gramsci A. (1971). Selections from the Prison Notebooks. In Hoare Q. and Nowell-Smith, G. (ed). Londres: Lawrence and Wishart.

Gutiérrez, F. y Barón. (2004). Crisis States Research Centre Re-stating the State: Paramilitary Territorial Control andPolitical Order in Colombia (1978-2004). Bogotá: Iepri, Universidad Nacional de Colombia

Gonzáles, F. (2014). Poder y violencia en Colombia. Bogotá: Cinep/Odecofi/ Colciencias. 
Harvey (2004). The 'new' imperialism: accumulation by dispossession. Socialist Register, 40, 63-87

IgAC. (2016). Atlas de la Distribución de la Propiedad Rural en Colombia. Bogotá.

IPC. (2012). Reclamante de tierras en Urabá: actividad de alto riesgo. Medellín: Observatorio n. ${ }^{\circ} 15$ de Derechos Humanos.

Leal, B. (2003). La doctrina de seguridad nacional: materialización de la Guerra Fría. América del Sur Revista de Estudios Sociales, 15, junio, 74-87.

onu. Comisión de Derechos Humanos (1998). Principios Rectores sobre los desplazamientos internos. E/CN.4/1998/53/Add.2

Tobón, W. (2001). Colonización armada, poder local y territorialización privada. Journal of Iberian and Latin American Research, 7 (2), 68-31.

Uaeriv. (1 de 4 de 2017). Registro Único de Unidad de víctimas. En línea. Recuperado de: http://rni.unidadvictimas.gov.co/RUV

Vidal, R. (2005). Derecho global y desplazamiento interno. Bogotá: Editorial Javeriana.

Vidal, R. C., Salcedo, J. A., y Medina, A. (2011). Desplazamiento forzado y construcción de paz en Colombia 2009-2010. Bogotá: CODHES-Universidad Javeriana 